\title{
Study of outcome after fracture reduction and internal fixation with volar locking plates in distal end radius fractures
}

\author{
Ramnath D. $S^{1}$, Ravikiran $\mathbf{N}^{2}$, Kolla $S^{3}$ \\ ${ }^{1}$ Dr. D. S. Ramnath, Professor In charge, Govt Medical College, Nizamabad, ${ }^{2}$ Dr. Ravikiran. N, Assistant Professor, \\ Osmania Medical College, Hyderabad, ${ }^{3}$ Dr. Saketh Kolla, Senior Resident, Osmania Medical College, Hyderabad, \\ Dr. Abhinandan Reddy. M Senior Resident Osmania Medical College-Hyderabad, India.
}

Address for correspondence: Dr. Ravikiran. N, Email: drnrkiran@gmail.com

\begin{abstract}
Background: The distal end radius fractures are common in older age group patients with osteoporosis. There are many treatment modalities both operative and non-operative methods. In osteoporotic patients the volar locking plate fixation may be the best option after open reduction. Our study aim is to assess the functional outcome in a retrospective study. Methods: 30 patients in age group of 50-70, with mean age of 60 years, with distal end radius fractures were selected and fixed with volar locking plates after open reduction by anterior incision. These patients were followed retrospectively for period of 12 months mean (24 months follow up). The modified MAYO score and DASH (disabilities of the Arm Shoulder and Hand) scores were used to assess the outcome- functional and fracture union. Results: About $80 \%$ got good to excellent, $15 \%$ satisfactory, and $5 \%$ poor results according to the mayo and dash scores. Conclusion: The volar locking plate fixation after open reduction yield good to excellent results, among the treatment options available for distal end radius fractures.
\end{abstract}

Key words: Distal end radius fractures, Open reduction \& internal fixation, Volar locking plates

\section{Background}

The distal end radius fractures are more common in old age group, especially in females after menopause. This is due to increased activity levels. The fractures may be intra-articular, extra articular, comminuted or not, and may be due to high energy trauma, in younger age group. The most common method of injury is due to fall on out stretched hands. There are various methods of treatments available. Both operative and conservative.

Sex and age influence the distal end radius fractures. These are common in all age groups. Most common in older females due to osteoporosis, simple fall from standing height can cause fracture [1]. In younger age groups the road traffic accidents and injuries due to outside sport activities may cause distal end radius fractures [1]. Incidence of distal radius fractures was in rising trend for the last 5 decades $[2,3]$. This trend is also present in INDIA \& U.S, in age group of 60-70

Manuscript received $27^{\text {th }}$ April 2016

Reviewed: $10^{\text {th }}$ May 2016

Author Corrected: $25^{\text {th }}$ May 2016

Accepted for Publication $13^{\text {th }}$ June 2016 years females and about 300-400 cases per 100000 people years. The overall lifetime risk is $15 \%$ and these are the first most common fractures in post menopause. These fractures also indicate future possible fragile fractures of hip, spine. [2,3]

Risk Factors for fractures of distal end radius: -

1. Female gender

2. Hereditary

3. Ethnicity

4. Osteoporosis

5. Post menopause. [3,4]

Various methods of fracture treatments: -

1. Conservative- manipulative reduction and cast application.

2. MRD and ligament taxis with external fixator.

3. Open reduction and fixation with ELLIES PLATES.

4. Open reduction and fixation with $\mathrm{k}$-wires.

5. Open reduction and fixation with volar locking plates. [4] 
Our study is retrospective study and the aim is to study functional out come after open reduction and internal fixation with volar locking plates.

\section{Methods}

Our study is retrospective study. the patients selected were in the age group of 50-70 years, using data base of hospital records. Most of the patients were females with osteoporosis.

The study conducted between 2012 to 2015 .

\section{Inclusion Criteria-}

1. Distal end radius fractures with intra-articular extension

2. Fractures with displacement of more than $2 \mathrm{~mm}$.

3. Fractures with shortening more than $3 \mathrm{~mm}$.

4. Fractures with angulation more than 15 degrees.

5. Metaphyseal fractures with comminution.

6. Old non operative cases, those lost reduction.

The mean time of surgery is 14 days. Range 0-28 days after fracture.

\section{Exclusion Criteria}

1. Fractures more than 28 days old

2. Those treated with other implants.

3. Non traumatic lesions.

Patients: -Using hospital records, and above inclusion criteria, 30 patients were selected and the $\mathrm{x}$-rayspreoperative, post-operative, case sheet analysis, intraoperative findings, questionnaire regarding function and range of motion were analyzed.

Results were assessed using modified MAYO SCORES and QUICK DASH SCORES (disabilities of arm, shoulder and hand).

\section{Dash and quick dash scores}

Dash- The Disabilities of the Arm, Shoulder and Hand (DASH)-

\section{Mayo Wrist Score: -}

During the last four -4 weeks the patients will answer the 12 multiple choice questions in 4 sections. [8]

Section 1 - Pain Intensity

No pain

Mild Occasional

Moderate, tolerable

Severe to intolerable
1. Self-reportingquestionnaire

2. Measures symptoms and physical function

3. Outcome of 30-item

4. Describes the disability.

5. Monitor changes in function and symptoms over time. [5,6,7]

Quick Dash- Quick DASH. It contains eleven items and is similar with regard to scores and properties to the full DASH. A comparison of item-reduction approaches suggested that the retention of clinically sensible and important content produced a comparable, if not slightly better, instrument than did more statistically driven approaches. - [7]

This is a shorter form of questionnaire.

It contains only 11 questions that should be answered by patients in the last week.

In 2002 a revised scoring system was introduced by DASH

\section{SCORING THE DASH $[6,7]$}

Two components of the DASH: the disability/ symptomquestions (30 items, scored 1-5) and the optional high performance sport / music or work section (4 items, scored 1-5). DASH

disability/symptom score $=($ sum of $\mathrm{n}$ responses $)-1] \mathrm{x}$ $25 / n$

where $\mathrm{n}$ is equal to the number of completed responses. 27 of the 30 items should be completed to becalculated. The values for all completed responses aresummed and averaged, producing a score out of five. This value is then transformed to a score out of 100 by subtractingone and multiplying by 25 . This is done to makethe score easier to compare to other measures scaled on a 0-100 scale. Greater disability means higher score.
Section 2 - Functional Status

Returned to regular employment

Restricted employment

Able to work, but unemployed

Unable to work because of pain 
Section 3 - (choose either $3 a$ or $3 b$ )

3 a - Range of Motion (\% of normal side)
$100 \%$
$75-99 \%$
$50-74 \%$
$25-49 \%$
$0-24 \%$

$3 \mathrm{~b}$ - If only injured hand examined

Greater than 120 degrees

0 -120 degrees

60-90 degrees

30-60 degrees

less than 30 degrees

Section 4 - Grip strength \% of normal

The Mayo Wrist Score is

$100 \%$

$75-100 \%$

$50-75 \%$

$25-50 \%$

\section{Interpretation: -}

90-100 - excellent

$80-90-$ good

60-80 - satisfactory

$<60-$ poor

Results according to mayo wrist scores, quick dash scores.

\begin{tabular}{|l|l|l|}
\hline & Mayo Wrist Score & Dash Score \\
\hline Excellent & $90-100$ & $0-5$ \\
\hline Good & $80-90$ & $6-15$ \\
\hline satisfactory & $60-80$ & $16-35$ \\
\hline Poor & $<60$ & $>35$ \\
\hline
\end{tabular}

100 score is excellent in MAYO WRIST SCORE and 100 is poor in DASH SCORE [5, 6, 7, 8]. x-rays both preoperative and postoperative were analyzed for fracture classification and union of fractures. Pain on pressure (tenderness) at fracture site is also assessed for union clinically. The classification used was AO-ASIF CLASSIFICATION. Radiographic callus formation and trabecular formation is regarded as union.

Surgical Technique- Regional anesthesia or general anesthesia was given accordingly and through anteriorly given incision, besides flexor carpi radialis and its bed, fracture sites were freshened, reduced and fixed with routine locking volar plates. Specific type of the implant was used in all cases. Routine bone grafting was not done. Requirement for decompression of carpal tunnel was not there routinely. Below elbow pop slabs were applied for a period of 4-6 weeks and removed after radiological and clinical union changes. Physiotherapy exercises were employed.

\section{Results \& Discussion}

About $80 \%$ got good to excellent $(n=24), 15 \%$ satisfactory $(n=4)$, and $5 \%(n=2)$ poor results according to the mayo and dash scores. $90 \%$ - females, $10 \%$ males.

24 patients - excellent to good results

4- patients - satisfactory results

2- patients - got poor result.

The different variables were distributed (continuous and categorical variables) and calculated by using percentages, median and standard deviation statistic techniques. 


\section{Results in tabular form}

\begin{tabular}{|l|l|l|}
\hline & Mayo Wrist Score & Dash Score \\
\hline Excellent & 17 & 18 \\
\hline Good & 7 & 6 \\
\hline satisfactory & 4 & 4 \\
\hline Poor & 2 & 2 \\
\hline
\end{tabular}

Age wise distribution: -

$70 \%$ - are in the age range of 60-70years

$20 \%$ - are in the range of 55-60 years.

$10 \%$ are in the range of 50-55 years.

The above variable factors- sex, age, were not influencing the outcome.

The fracture classification groups according to AO-ASIF CLASSIFICATION [9,10]: -

The total A GROUP- 50\% (combined 23-A1, A2, A3.)

B GROUP-20\% (COMBINED 23-B1, B2, B3.)

C GROUP-30\% (COMBINED 23-C1, 2, 3)

The total follows up period was 24 months post-operatively. Mean follow up period was 12 months. [10]

Analysis of x-rays-The post-operative follow up x-rays were analyzed for fracture union. The fractureunionwas delayed in group c patients, where comminuted fractures were there. The mean union time was 8.6 weeks (6-30 weeks).

The assessment was based on trabecular formation (bridging) in the $\mathrm{x}$-rays both in A. P AND LAT views. [11]radiological assessments. Clinically- the assessment for union was no tenderness at fracture site. [11]

Complications: -Therewere superficial incision site infections in 4 patients, cured after antibiotic therapy. In 6 members mild to moderate stiffness developed and after physiotherapy recovered well. Prominent dorsal screws in 3 members. There were no tendon ruptures and chronic regional pain syndromes.

\section{Discussion}

The most common cause is fall on out stretched hand. There are two age groups most commonly affected. The pediatric age group between 6-10 years and the other age group is geriatric, (60-70). [11,12]. In younger age group high energy motor vehicle accidents cause these fractures. In older people- simple fall can cause distal radius fractures. $[11,12]$.

High load is imparted to the distal radius by carpal bones when the person falls on the outstretched hand. In younger people high energy is required. In geriatric people low energy is sufficient to break the distal radius. [12]. The type of fracture and degree of comminution depends on various factors. $[12,13]$

Factors affecting the nature and type of fractures:-

1. Quality of bone

2. Nature of fall

3. Age of the patient

4. Weight of the patient

5. Type of the energy.

6. Position of the hand and wrist at the time of impact.
The combinations of the above factors may cause different types of fracture combinations. Distal cortex fails in compression-causing more comminution on dorsal side. Volar cortex fails in tension. [12,13]

\section{Treatment Protocol: -}

Non-operative treatment (closed reduction and casting) Surgical treatment

Plate fixation

External fixation A bridging external fixator device, A non-bridging external fixator, Dynamic hingedexternal fixation

Closed reduction with percutaneous pinning $[13,14]$

Factors Affecting Treatment:-

Patient-related:- Age, Osteoporosis, Work-related injuries. [15,16]

Fracture characteristics:-

Un-displaced fractures-treated conservatively

Displacement- laterally $>1 \mathrm{~cm}$, radial shortening $>5 \mathrm{~mm}$, comminution, intra- articular fractures, associated ulnar 
fractures, compound fractures- require surgical treatment $[16,17]$

ComparativeStudies:- we compared our results with the studies of others.

\section{Our Results}

About $80 \%$ got good to excellent $(n=24), \quad 15 \%$ satisfactory $(n=4)$, and $5 \%(n=2)$ poor results according to the mayo and dash scores, as compared to the studies below.

The studies of Joideep phadnis et al [17] have shown The median DASH score was 2.3 and median MAYO score was 90 for the whole group. Overall, 133 patients (74\%) had a good or excellent DASH and MAYO score. Statistical analysis showed that no specific variable including gender, age, fracture type, postoperative immobilization or surgeon grade significantly affected outcome. Complications occurred in 27 patients $(15 \%)$ and in 11 patients were major (6\%). And Results of Rozental et al [18] were compared with our results which were also shows almost similar outcome.

Those were few studies with functional outcome analysis after volar fixation with locking plates after open surgical procedure. Those studies also show 70$80 \%$ good to excellent functional results, $15-20 \%$ satisfactory to poor results using DASH SCORES. In all studies poor functional outcome was due to complications.

Complications: The possible complications- Deep infections- at bone level, superficial surgical site infections, mal-union, carpal tunnel syndrome, tendon ruptures. [19'20]. The other complication -tenosynovitis may be present. [21, 22]. Correct reduction under c-arm guidance before plate fixation (both in A.P \& LAT views), good preoperative sterility maintenance, good surgical technique, less soft tissue damage reduces complications. [23, 24, 25]

\section{Conclusion}

The study shows that the fixation of distal end radius fractures with volar locking plate, results in good to excellent union and functional outcome. Because of complications like infection, improper reduction before fixation may lead to poor functional outcome. The volar locking plate fixation after open reduction can be executed in all types of distal end radius fractures.
Funding: Nil, Conflict of interest: None initiated. Permission from IRB: Yes

\section{References}

1. Macintyre $\mathrm{Nj}$, Dewan N.Et Al Epidemiology Of Distal Radius Fractures And Factor Spredicting Risk Prognosis. J Hand Ther. 2016 Apr-Jun;29(2):136-45. Doi: 10.1016/J.Jht.2016.03.003. Pmid: 27264899.

2. Elisabeth Brogren, 1 Michael Petranek, 2 and Isam Atroshi1 Incidence and characteristics of distal radius fractures in a southern Swedish regionbmc Musculoskeletal Disord. 2007; 8:48. Published online 2007 May 31. Doi:10.1186/1471-2474-8-.48 PMCID: PMC1904215.

3. Roop Bhushan Kalia, Alok C AgarwalsymposiumFRAGILITY FRACTURES, Year:2014,Volume:7, Issue:2, Page : 113-118, Fragility Fractures of the Distal Radius, Date of Web Publication14-Sep-2015DOI: 10.4103/0975-7341.1652355).

4. Javed S, Shahid R, Thimmiah R, El-deen M. distal radius fractures volar locking plate osteosynthesis for distal radius fractures. J Orthop Surg (Hong Kong). 2015 Dec;23(3):323-6.

5. Hudak PL, Amadio PC, Bombardier C. DASH AND QUICK DASH SCORES.Am J Ind Med. 1996 Jun; 29 (6):602-8. Erratum in: Am J Ind Med 1996 Sep; 30 (3):372. (http://www.dash.iwh.on.ca/).

6. Angst, F., Schwyzer, H. K., Aeschlimann, A., Simmen, B. R., \& Goldhahn, J. (2011). Arthritis care \& research, 63 (S11), S174-S188. http://onlinelibrary. wiley.com/doi/10.1002/acr.20630/full.

7. Beaton DE1, Wright JG, Katz JN; Upper Extremity Collaborative Group Development of the Quick DASH: comparison of three item-reduction approaches. J Bone Joint Surg Am. 2005 May; 87(5):1038-46. PMID: 15866967.

8. Amadio PC, Berquist TH, Smith DK, Ilstrup DM, Cooney WP 3rd, Linscheid RL. Mayo Wrist Score Reference for Score: Scaphoid malunion. J Hand Surg [Am]. 1989 Jul;14(4):679-87.www. orthopaedic scores.com

9. Online book-ao surgery reference online, ao foundation, https://www2.aofoundation.org/wps/portal/! ut/p/a1/04 
10. Marsh J: OTA Fracture Classification- image. J Orthop Trauma. 2009, 23 (8): 551-10.1097/BOT. 0b013e3181ad5e92. PMID: 19704268.

11. Corrales LA1, Morshed S, Bhandari M, Miclau T 3rd.Variability in the assessment of fracture-healing in orthopaedic trauma studies. J Bone Joint Surg Am. 2008 Sep;90(9):1862-8. doi: 10.2106/JBJS.G.01580.

12. JB Jupiter - J Bone Joint Surg Am, 1991-sites. surgery. northwestern. edu Jupiter JB. Current concepts review: fractures of the distal end of the radius. J Bone Joint Surg Am. 1991Mar;73(3):461-9.

13.British Medical journal- Wrist fractures- BasicsPathophysiology- Best Practice- English bestpractice. bmj.com/best-practice/monograph//pathophysiology. htmlMar 21, 2016.

14. Ezzat A, Baliga S, Carnegie C, Johnstone A. volar locking plate fixation for distal radius fracture- does age affect outcome? PMID: 27053837).

15. Online guidelines- electronic book-appropriate use criteria for treatment of distal radius fractures. http:// www.aaos.org/research/guidelines/drfguideline.pdf.

16. F. Leung, K. Kwan, C. Fang -notes. Distal radius fracture: current concepts and management, The Bone \& Joint Journal.http://www.boneandjoint.org.uk/content/ focus/distal-radius-fracture-current-concepts-andmanagement.

17. j.phadnis et al. midterm functional outcome after the internal fixation of distal end radius fractures journal of orthopedic surgery and research 2012,7.4 mid-term functional outcome after the internal fixation of distal radius.josr-online.biomedcentral.com/articles/10.1186/ 1749-799x-7-4, by j phadnis - 2012 18. doi: 10.1186/1749-799x-7-4@ phadnis et al; licensee biomed central ltd. 2012.

18. Rozental TD, Blazar PE: Functional outcome and complications after volar plating for dorsally displaced, unstable fractures of the distal radius. J Hand Surg Am. 2006, 31: 359-65. 10.1016/j.jhsa.2005.10.010.
19. Lee DS1, Weikert DR2. Complications of Distal Radius Fixation. Orthop Clin North Am. 2016 Apr; 47(2):415-24. doi: 10.1016/j.ocl.2015.09.014.

20. Satake H, Hanaka N, Honma R, Watanabe T, Inoue S, Kanauchi Y, Kato Y, Nakajima T, Sato D, Eto J, Maruyama M, Naganuma Y, Sasaki J, Toyono S, Harada M, Ishigaki D, Takahara M, Takagi M. complications of distal radius fractures treated with volar locking plates. Orthopedics. 2016 May 23:1-4. doi: 10.3928/01477447-20160517-05.

21. Tarallo L1, Mugnai R, Zambianchi F, Adani R, Catani FVolar plate fixation for the treatment of distal radius fractures: analysis of adverse events. J Orthop Trauma. 2013 Dec; 27(12):740-5. doi: 10.1097/BOT. 0b013e3182913fc5

22. Young Hak Roh, MD, Beom Koo Lee, MD, PhD, Jung Ho Noh, MD, Joo Han Oh, MD, PhD, Hyun Sik Gong, MD, PhD, Goo Hyun Baek, MD, PhD, Factors Delaying Recovery After Volar Plate Fixation of Distal Radius Fractures, Journal of hand surgery, DOI: http:// dx.doi.org/10.1016/j. jhsa. 2014.04.033, August 2014 Volume 39, Issue 8, Pages 1465-1470).

23. Chris Dillingham, MaryBeth Horodyski, Aimee M. Struk, and Thomas Wrigh, Rate of Improvement following Volar Plate Open Reduction and Internal Fixation of Distal Radius Fractures, Advances in Orthopedics, Volume 2011 (2011), Article ID 565642, 4 pages, http://dx.doi.org/10.4061/2011/565642.

24.Wong, K K; Chan, K W; Kwok, T K; Make, K H. Volar fixation of dorsally displaced distal radial fracture using locking compression plate Journal of Orthopaedic Surgery13.2 (Aug 2005): 153-7. Functional Outcome and Complications After Volar Plating for Dorsally Displaced, Unstable Fractures of the Distal Radius.

25.xPillukat T, Fuhrmann R, Windolf J, van Schoonhoven $J$. the volar locking plate for extension fractures of distal radius. Oper Orthop Traumatol. 2016 Feb; 28(1):47-63; quiz 64. doi: 10.1007/s00064-0150433-5. Epub 2015 Dec 17. German.

\section{How to cite this article?}

Ramnath D. S, Ravikiran N, Kolla S. Study of outcome after fracture reduction and internal fixation with volar locking plates in distal end radius fractures. Int J Med Res Rev 2016;4 (6):987-992.doi: 10.17511/ijmrr.2016.i06.21. 